\title{
Estresse docente na Educação Infantil: um estudo so- bre professores de creches públicas de uma cidade do Estado do Rio de Janeiro
}

O artigo investiga a presença do estresse no cotidiano profissional dos professores da Educação Infantil. São apresentadas algumas considerações a respeito da formação dos educadores e do novo contexto de mudanças vivenciado na educação. Diante desta problemática, realizou-se pesquisa com 100 professores de creches públicas de uma cidade do Estado do Rio de Janeiro/ Brasil, a fim de investigar possíveis fatores estressores em seu ambiente de trabalho. A análise dos dados indicou a presença de fatores estressores que parecem estar relacionados a fatores contextuais e que há carência de preparação para administrá-los, uma vez que o tema não vem sendo sistematicamente abordado nos seus cursos de formação continuada. Sendo assim, torna-se necessário que esta temática seja tratada nos cursos de formação inicial e continuada, a fim de promover a discussão sobre os fatores estressores, aliada à implementação de políticas públicas educacionais, de modo a resguardar o bem estar dos professores deste nível educativo.

Palavras-chave: Estresse Docente; Educação Infantil; Formação Inicial; Formaç̧ão Contínua

\section{Teacher stress in early childhood education: a study of public day care teachers from a city in the state of Rio de Janeiro}

The article investigates the presence of stress in the daily work of early childhood education teachers. Are some considerations regarding the training of teachers and the new changes of context experienced in education. Faced with this problem, there was study of 100 teachers at public kindergartens from a city in the state of Rio de Janeiro/Brazil, to investigate possible stressors in their work environment. Data analysis indicated the presence of stressors that appear to be related to contextual factors and that there is a lack of preparedness to manage them, since the issue has not been systematically addressed in their continuing education courses. Therefore, it is necessary that this issue be addressed in initial and continuing education courses in order to promote discussion on stressors, combined with the implementation of educational policies in order to safeguard the welfare of teachers at this level education.

Keywords: Teacher stress; Early childhood education; Initial training; Continuing training

\footnotetext{
I Graduada em Licenciatura em Pedagogia no Instituto Superior de Educação Professor Aldo Muylaert (ISEPAM), Professora de creche municipal em Campos dos Goytacazes/RJ. E-mail: quelenpimentel@hotmail.com

2 Doutoranda em Educação da Universidade Federal de Juiz de Fora (UFJF)/MG. Professora do Curso de Licenciatura em Pedagogia no Instituto Superior de Educação Professor Aldo Muylaert (ISEPAM). E-mail: carlapqcorrea@hotmail.com
} 


\section{Introdução}

O estresse ocupacional é causa de muitos problemas para o trabalhador brasileiro. Geralmente, este tipo de mal estar não fica restrito ao ambiente de trabalho, mas passa a fazer parte da vida do indivíduo, prejudicando sua saúde física e mental. Causado por inúmeros fatores, este tipo de problema tem acometido significativamente os professores. Estudos mostram como o mal estar profissional vai surgindo lentamente, podendo agravar-se, chegando ao quadro da Síndrome de Burnout (ESTEVE, 1999; REINHOLD, 2002; LANTHEAUME, 2012).

Diante da atual conjuntura, o objetivo deste trabalho consiste em verificar a presença de fatores estressores no cotidiano profissional de professores de creches públicas de uma cidade do Estado do Rio de Janeiro.

Para atingir o objetivo proposto, primeiramente o artigo discute os fatores estressores que geram o mal estar nos profissionais de educação em sua prática, afetando sua vida pessoal. Após, contextualiza-se o cenário da Educação Infantil no país, indicando as dificuldades que vem sendo enfrentadas pelos professores de creches e pré-escolas, que podem levá-los ao adoecimento e à insatisfação no trabalho (KRAMER, 2002, SILVA, 2002; KISHIMOTO, 2002; VIEIRA; OLIVEIRA, 2013).

Finalmente, apresenta-se a pesquisa realizada em uma cidade do Estado do Rio de Janeiro, com 100 professores de Educação Infantil, que atuam com crianças de 0 a 3 anos em creches municipais, a fim de investigar a presença de fatores estressores no cotidiano profissional.

Espera-se, com este trabalho, contribuir ao debate acerca da temática do estresse docente, que uma vez vivenciado sistematicamente pelos profissionais da educação, pode trazer sérias consequências, tanto aos professores envolvidos quanto às crianças com as quais interagem cotidianamente.

\section{Fatores estressores da docência}

Os dias atuais estão repletos de muitas inovações, trazendo em seu bojo mudanças significativas e exigências variadas, principalmente para a educação. Novas responsabilidades têm sido projetadas para os profissionais dessa área, sobretudo aos professores, levando-os a muitos desafios. 
Este cotidiano profissional pode afetar a saúde dos que atuam na educação da infância, na medida em que existem certos fatores que podem se tornar fonte de estresse. Uma vez vivenciados sistematicamente, estes fatores estressores podem levar o professor a experimentar um sentimento de mal-estar ao exercer a docência.

Os fatores estressores na docência são variados e dependem do contexto de trabalho de cada professor. Como exemplos destes fatores podem ser citadas a falta de estrutura de creches e pré-escolas, a superlotação de turmas de crianças para cada professor, a formação destes profissionais, dentre outros fatores.

Segundo Esteve (1999), os cursos de formação inicial de professores vêm desenvolvendo seu trabalho a partir de enfoques normativos que já trazem um modelo de professor preestabelecido, “o bom professor", e a partir daí os métodos e procedimentos são traçados, definem-se os conceitos e mostram até mesmo o que não deve ser feito, para não criar contradições ao modelo educacional que se quer implantar, esquecendo-se que a prática diária é permeada por carências e contradições que nem sempre permitem fazer o que se pretende e que pedagogicamente se quer que faça.

Desta forma, quando o professor tem o seu primeiro contato com a docência seu encantamento pode ser prejudicado, pois não se encontra preparado para agir de outra maneira a não ser aquela aprendida no seu curso de formação. A abordagem normativa além de exercer forte influência no comportamento do professor, pode trazer efeitos adversos para sua personalidade, já que esses enfoques montam um estereótipo de profissional difícil de alcançar, pois as qualidades demandadas a um professor ideal são inacessíveis.

Para Aguiar e Almeida (2008), os professores vivem em crise de identidade por estarem fixados à imagem do "eu" ideal e apesar de necessitarem do outro para lhe dar crédito, vivem sozinhos em meio a uma sociedade que se tornou individualista, na qual a distância elimina cada vez mais a certeza de se constituir como sujeito e de se sentir protegido. Nessas circunstâncias suas vontades e aflições são silenciadas.

Desprevenidos e surpreendidos por um contexto totalmente desproporcional ao que até então tinha se ouvido falar, com carências estruturais, pedagógicas e outras, os professores podem desenvolver certas ansiedades, uma vez que não conseguem colocar em prática todos os ideais pedagógicos ensinados nos cursos de formação inicial. Este quadro conjuntural é capaz de provocar 
Estresse docente na Educação Infantil: um estudo sobre professores de creches públicas de uma cidade do Estado do Rio de Janeiro

um mal-estar relacionado ao exercício profissional.

Para Lantheaume (2012), o mal-estar docente está relacionado principalmente com sua atuação em sala de aula, quando não consegue realizar o ofício próprio da profissão docente, ensinar. O professor pode desenvolver um sentimento de fracasso diante de seus colegas, o que o impede de buscar ajuda, pois sente vergonha da sua incapacidade.

Segundo Aguiar e Almeida (2008), o mal-estar está presente na docência, pois é uma atividade que se desenvolve a partir da interação entre as pessoas, o que expõe o professor a uma variedade de sentimentos. Os sintomas desse mal-estar estão presentes em toda a atividade que o docente vai promover, que não se expressa em palavras, mas se traduz nas suas atuações que demonstram fragilidade psíquica. Portanto, o adoecimento do professor não deve ser visto apenas no âmbito biológico, mas nas manifestações de mal-estar vividas no ambiente profissional devido aos fatores estressores do cotidiano. O excesso de trabalho, o grau de envolvimento nele, nas relações que desenvolvem com os parceiros envolvidos no processo, os poucos recursos oferecidos para realizá-lo e sua própria forma de pensar vêm adoecendo o professor.

Assim, fatores contextuais interferem diretamente sobre a atuação docente e podem provocar certo abatimento nesse profissional. $\mathrm{O}$ ritmo em que são feitas as exigências se opõe à falta de meios e de tempo para se preparem. A exigência em promover métodos pedagógicos inovadores, muitas vezes, não está de acordo com o tipo e o número de materiais disponibilizados, sem falar nas salas cheias e o número de instituições sucateadas, o que pode levar muitos docentes a permanecerem na rotina de sempre.

Quando as forças se acabam, a situação passa a ser demonstrada por inúmeras formas, como, por exemplo, a queda do desempenho e a falta de vontade de estar em sala. Embora o sofrimento seja algo natural do ser humano, as formas de sofrimento de cada professor variam conforme o ambiente profissional em que está inserido e às experiências vividas.

Para Aguiar e Almeida (2008), a vida moderna, a sociedade e a família estão passando por uma crise moral e ética. A escola e a instrução dada pelo professor têm sido vistos como referência e/ou responsáveis por passar valores que são de incumbência da família. No entanto:

As demandas dos pais de que o professor tem de ensinar tudo a seus filhos, desde o respeito ao professor e às autoridades, na escola, a um comportamento social adequado e o respeito às normas, têm um efeito devastador na vida do professor. (...) Muitos por não conseguirem responder a essas questões, acabam frustrados, doentes, e carregam consigo um enorme sentimento de incompetência (AGUIAR; ALMEIDA, 
2008, p. 29).

Certas atitudes e comportamentos, como a falta de respeito das crianças, revelam a crise de sua educação familiar. Sem referências familiares importantes para viver em sociedade, as crianças por vezes chegam à escola com padrões morais e éticos diferentes do esperado, e o docente se vendo incapaz de executar a demanda dos pais, pode internalizar um sentimento de culpa, associando como fracasso profissional.

De acordo com Meleiro (2002), as crianças têm crescido cada vez mais sem limites e a família tem atribuído aos educadores, principalmente aos que estão iniciando o processo de socialização de seus filhos, a função de discipliná-los. Para Malagris (2002), na primeira infância, os professores exercem um papel muito importante na transmissão dos conhecimentos de mundo e que nesta fase acontece através das relações interpessoais, pelas quais a criança "vai, pelo contato com o professor e os colegas, gradativamente desenvolvendo atitudes, assimilando valores e exercitando habilidades" (MALAGRIS, 2002, p. 42).

Com o tempo, nessa relação de troca com parceiros diferentes, o conhecimento vai sendo construído, o professor vai se desenvolvendo enquanto profissional e as crianças vão formando sua personalidade. Nesta dinâmica desenvolve-se todo o trabalho na Educação Infantil, que segundo a Lei de Diretrizes e Bases da Educação Nacional, no 9.394/96, objetiva "o desenvolvimento integral da criança de até 5 (cinco) anos, em seus aspectos físico, psicológico, intelectual e social, complementando a ação da família e da comunidade” (BRASIL, 1996, artigo 29).

Entretanto, esta troca entre o professor e a criança pode enfrentar adversidades no cotidiano das creches e pré-escolas, uma vez que as crianças podem trazer certos desajustes em seu comportamento e muitos professores têm apresentado dificuldades ao interagir com elas, o que pode causar algumas reações ao quadro de estresse vivenciado.

\section{Reações do estresse docente e estratégias de enfrentamento}

Nesse contexto de estresse vivenciado por muitos professores, expressões de sofrimentos psíquicos podem aparecer e seus sintomas podem ser um meio encontrado por eles de não ter que falar da sua incapacidade. Tais sintomas podem levar o professor à síndrome de burnout, caracterizada por uma reação orgânica que surge quando o indivíduo se expõe demais aos fatores estressores 
Estresse docente na Educação Infantil: um estudo sobre professores de creches públicas de uma cidade do Estado do Rio de Janeiro

(AGUIAR; ALMEIDA, 2008).

No entanto, Reinhould (2002) ressalta que até se chegar à síndrome, o professor passa por diversas fases na profissão, a do idealismo/encantamento, na qual chega com muitas ideias e novos métodos; a do realismo, em que começa a perceber que as tentativas iniciais não surtiram tanto efeito, principalmente quanto ao reconhecimento e às recompensas, começando a considerar que o problema é com ele; a da estagnação e frustração, caracterizada pela falta de paciência, intolerância nos seus relacionamentos, demonstrando menos compromisso com horários, e responsabilizando os outros pelos problemas que na verdade são seus; até chegar à fase da apatia, na qual o burnout se instala totalmente, e, a pessoa não vê sentido no que faz, perdendo a confiança em si, não vendo condições futuras de melhora.

O burnout, segundo Reinhould (2002), é o mesmo que "consumir-se em chamas", ou seja, a frustração e a exaustão do trabalho vão consumindo a pessoa de pouco a pouco, até atingir tudo que faz parte de sua vida. Assim, a docência caracteriza-se como uma das profissões que mais possui situações favoráveis ao aparecimento do burnout, que se inicia de forma quase imperceptível, mas vai aumentando conforme vai diminuindo o prazer de lecionar.

O burnout:

É um risco ocupacional a que estão expostas especialmente as pessoas que trabalham em profissões de ajuda, as quais têm como traço em comum os contatos interpessoais muito intensos - como acontece com os professores. (...) se instala muitas vezes a partir de expectativas elevadas e não realizadas (REINHOLD, 2002, p. 65).

Esta síndrome acomete com mais frequência profissionais que desenvolvem seu trabalho em prol de outras pessoas e por isso precisam interagir diretamente com elas. Para ajudá-las, criam expectativas que não conseguem realizar devido a limitações da prática e quando ainda assim conseguem, não têm reconhecimento. Por isso, os professores que se envolveram mais no início de seu trabalho têm certa tendência a desenvolver a síndrome.

Reinhoud (2002) enfatiza que o burnout é o desaparecimento de energia e disposição, ocasionado por um estresse crônico e duradouro. É um processo que vai se iniciando paulatinamente na medida em que o entusiasmo e a dedicação vão cedendo lugar à frustração por não conseguir realizar o trabalho. Uma vez desiludido, o professor realiza um trabalho mecânico, comprometendo a qualidade da sua atuação. Assim, passa a demonstrar certa vulnerabilidade para desenvolver problemas físicos, cognitivos e emocionais. 
Segundo Lipp (2002), todas as pessoas podem desenvolver o estresse, mas seus sintomas podem variar de pessoa a pessoa, dependendo de qual fase se encontra. Ao lidar sempre com aspectos estressores, a pessoa pode chegar ao limite da sua resistência, e chegar à fase da quase-exaustão. Além do burnout, a depressão/transtorno de humor também se inicia nessa fase. O professor começa a sofrer, sentindo-se infeliz, sua criatividade e produção são prejudicadas e não sente mais vontade de estar perto dos alunos, procurando o isolamento.

Diante deste sofrimento vivenciado no cotidiano profissional, o professor sente a necessidade de buscar estratégias para lidar com a situação. Uma destas estratégias, segundo Esteve (1999), tem sido a necessidade de ausentar-se da instituição em que trabalha. $\mathrm{O}$ absentismo tem sido uma forma de reação adotada para driblar as tensões da profissão e fugir por algum tempo dos problemas enfrentados sem ter que abandonar definitivamente a docência.

Aguiar e Almeida (2008, p. 45) enfatizam que o afastamento por atestados médicos, licenças, "qualquer coisa que ateste seu mal-estar, que os tire do confronto com as impossibilidades relativas ao seu próprio desejo" são as formas que o docente encontrou de sair de cena quando não há mais recursos pessoais para lidar com a demanda.

Outra estratégia, segundo Esteve (1999), seria a inibição, quando o professor não se implica pessoalmente no trabalho, não acrescentando nada além do que é feito cotidianamente.

A profissão docente se desenvolve a partir das relações estabelecidas entre alunos e professores, que não podem acontecer sem envolvimento, principalmente o emocional. Sem ele a relação se torna fria e técnica, modificando o caráter da profissão.

Na Educação Infantil este âmbito relacional da profissão é ainda mais enfatizado, devido à tenra idade das crianças, requerendo do professor significativa sensibilidade às suas descobertas, angústias, medos, alegrias, dentre outros sentimentos comumente experimentados pelas crianças das creches e pré-escolas.

Neste contexto, destaca-se a formação inicial do professor como elemento fundamental de preparação para o cotidiano da Educação Infantil e a formação continuada como oportunidade imprescindível de revisitar constantemente a prática pedagógica e até mesmo ressignificá-la.

Segundo Esteve (1999), para se evitar casos que repercutam diretamente na personalidade docente, os cursos de formação inicial de professores deveriam trabalhar com enfoques descritivos, 
realizando um trabalho de prevenção a partir das dificuldades já constatadas na docência, revendo concepções e buscando inserir novos processos de formação, para que ao chegarem ao magistério, já se sintam habituados ao ambiente, portando recursos suficientes para exercerem o ofício.

Além disso, Malagris (2002) ressalta que para diminuir a vulnerabilidade ao estresse e proporcionar boa qualidade de vida não só ao professor, mas também ao aluno, é necessário que a formação inicial ofereça uma educação profissional especializada para o docente perceber o que está acontecendo de errado, investigar a causa que explica o desajuste no comportamento dos alunos e buscar as soluções certas, pedindo ajuda, se for o caso, de outros profissionais, como também dos pais, não excluindo a criança do processo.

Para Lantheaume (2012), nessa atual conjuntura do ofício docente, o professor deve aprender a dominar suas próprias emoções e, ao vivenciar o problema, deve agir com cautela e não encará -lo como pessoal, já que uma atitude mal pensada evidencia seu despreparo. Responder a um aluno com grosserias e violência vai contra tudo que se entende como profissional de educação.

Neste contexto, Lipp (2002) ressalta que quando não é possível mudar o fator estressor, é preciso buscar estratégias de conviver com ele, tentando enxergá-lo antes que aconteça, para traçar formas de interagir com o problema, dialogando sobre isso com colegas de trabalho. Estas atitudes podem ajudar a conviver com o estresse diário da profissão sem causar danos à saúde e à qualidade profissional.

Contudo, parece que nenhuma técnica que atue no plano individual conseguirá acabar com o mal-estar docente, já que "é uma doença social produzida pela falta de apoio da sociedade aos professores, tanto no terreno dos objetivos do ensino como no das recompensas materiais e no reconhecimento do status que lhes atribui” (ESTEVE, 1999, p. 144).

Em contrapartida, Lipp (2002) pondera que o ser humano já criou o hábito de colocar a culpa do estresse em fatores externos, quando muitas vezes a dificuldade está dentro de si. Professores que querem passar valores de seu tempo de criança criam expectativas além do que é possível alcançar, comprometem-se em fazer o que era da função de outros, mantêm-se ansiosos, querem competir com os colegas, sempre estão apressados, não esquecem o que já passou, não admitem errar, criam internamente sua própria fábrica de estresse, e para eliminá-la, precisam "ser mais pacientes, tolerantes, menos perfeccionistas e aprender a identificar os pensamentos geradores de 
estresse, vigiando-os e corrigindo-os para torná-los mais adequados e lógicos” (LIPP, 2002, p. 119).

Aguiar e Almeida (2008, p. 46) ressaltam que os professores deveriam deixar de lado a ilusão de que o bem-estar deveria advir da capacidade de responder a todos os ideais culturais com a convicção de que tudo sabem e tudo podem, quando na verdade são sujeitos que falham, erram e se equivocam, entendendo que "até mesmo a posição de nada saber se faz necessária eventualmente, para que o aluno possa ascender ao desejo de conhecer".

Neste artigo, enfatiza-se o estresse do professor da Educação Infantil. Sendo assim, a seguir, apresenta-se brevemente a história deste nível educativo no país e as dificuldades enfrentadas pelos professores de creches e pré-escolas, gerando, muitas vezes, um cotidiano profissional de estresse e insatisfação.

\section{O contexto do professor da Educação Infantil}

O contexto vivenciado pelo professor de Educação Infantil nos dias atuais não pode ser compreendido sem uma breve incursão histórica na gênese deste nível educativo no país. Tal histórico é apresentado com base nos estudos de Oliveira (2010). Seus achados contextualizam a proposta deste artigo de refletir sobre a presença de fatores estressores no cotidiano profissional de professores de creches.

Segundo Oliveira (2010), a história da educação infantil só tem início no Brasil na metade do século XIX, época de declínio do sistema escravista e da estrutura colonial de produção, quando se intensifica o fluxo de pessoas nas grandes cidades e aumentam-se as chances do país se desenvolver culturalmente, tecnologicamente e economicamente, devido à possível industrialização e a substituição do governo de monarquias.

As primeiras tentativas de organização de creches, asilos e internatos surgiram em caráter assitencialista, com intuito de cuidar das crianças pobres, filhos de mulheres que trabalhavam fora de casa, órfãos e abandonados, fazendo com que a mortalidade infantil fosse diminuída, mas em contrapartida, os "problemas da infância" continuaram.

Neste contexto, tornava-se urgente um modelo de educação que estivesse à altura de uma nação moderna, que se consolidava a partir do novo modo de produção capitalista em desenvolvimento. Vem daí o grande motivo de importar os jardins de infância, um produto internacional, 
criado em meio ao progresso dos países estrangeiros, mas que não surtira grandes efeitos em nosso país, pois os jardins acabaram servindo apenas para guardar os infantes, contrariando o ideal liberal de educação da Europa, que diz ser de todos o direito à educação de qualidade.

Por volta do século XX, o modo de vida da população estava se modificando muito, devido ao processo de urbanização e industrialização. Muitas mulheres tinham que trabalhar para auxiliar nas despesas de casa, obrigando-as a deixarem seus filhos com as criadeiras, também conhecidas como "fazedoras de anjos", pois muitas crianças morriam em decorrência das péssimas condições higiênicas e de recursos, além de sofrerem problemas ocasionados por traumas decorrentes da separação da família.

Entre 1920 e o início de 1930, uma das pautas das reivindicações feitas principalmente pelas operárias referiu-se a lugares que pudessem guardar as crianças enquanto estivessem no trabalho. Nesse contexto de luta, os empresários laçaram uma política estratégica, que beneficiava às operárias com clubes esportivos, creches e escolas maternais, para que trabalhassem satisfeitas, o que aumentaria a produção. Assim, a creche passou a ser vista como algo rentável, não para as crianças e/ou para suas mães, mas um tipo de benefício que poderia gerar "bons frutos" à empresa da qual a mãe fazia parte.

Oliveira (2010) ressalta que as primeiras leis que regulamentavam o atendimento de crianças pequenas em escolas maternais e jardins de infância não se deram sem interesses. O desejo de ascensão social da pequena, média e grande burguesia foi o principal motivo de renovação do pensamento educacional. Portanto, a preocupação não era com a criança. Nesse momento, a creche serviria como ação momentânea para aliviar os problemas causados pela acelerada urbanização.

A política governamental dos militares pós-1964 continuava a divulgar a creche e a pré-escola como assistência à criança pobre. $\mathrm{O}$ tratamento aos infantes através de entidades de acolhimento filantrópicas, assistenciais e comunitárias se encarregava de prestar o acolhimento sem qualquer estrutura, a começar pelo pessoal responsável pelos programas, que realizava o trabalho sem qualquer preparação.

A defesa da creche e pré-escola, de acordo com Oliveira (2010), é intensificada em 1971, quando a grande massa de trabalhadores, entre eles as mulheres, passa a reivindicar lugares mais amplos em que seus filhos pudessem brincar, já que a urbanização diminuiu os espaços nas cidades. 
E apesar da Lei 5692/71 surgir no bojo dessas reivindicações, atribuindo aos sistemas de ensino o dever de cuidar da educação de crianças de 0 a 6 anos em escolas maternais, jardins de infância ou instituições equivalentes, não impediu que as crianças continuassem sendo privadas culturalmente, já que o atendimento feito nessas instituições não tinha o objetivo de educar para mudar a sua realidade de extrema pobreza, mas superar as condições sociais que estavam sujeitas a partir de uma educação compensatória, que as assegurava questões de alimentação e saúde.

Na década de 1970 e 1980, as desigualdades sociais eram tantas que não tinham como serem escondidas. As tensões sociais em busca de melhores condições de vida, entre elas o acesso à escola pelos mais pobres, foi um dos motivos do grande aumento de creches financiadas pelo poder público e privado.

Enquanto os países de primeiro mundo já gozavam de instituições que ofereciam um ensino de qualidade, com propostas inovadoras, segundo Oliveira (2010), o Brasil ainda continuava prestando "ajuda" à sociedade com serviços de péssima qualidade, sem cunho pedagógico e muito menos resgate e valorização cultural. Um trabalho limitado muitas vezes devido à falta de preparação profissional na área.

O modelo familiar/materno de cuidado e educação de crianças pequenas submeteu o profissional docente a uma formação precária, uma vez que o trabalho realizado nas creches era de caráter assistencialista e, por isso, não era preciso aprender conhecimentos sobre a educação infantil nem conhecimentos históricos. Bastava ter paciência, afetividade e controle para lidar com os pequenos, experiências que não exigiam qualificação específica e profunda. Apenas era preciso realizar com os filhos alheios o que já faziam com os seus. A diferença seria a remuneração para tal função.

Segundo Leite (2002), com a LDBEN no 9394/96, a oferta de creches e pré-escolas garantida pelo Estado não deve ser mais caracterizada pela educação compensatória e sim por uma educação que desenvolva a criança em seus aspectos físicos, psicológicos, intelectuais e sociais.

Mas, para Oliveira (2010), a concepção de construção do saber, proposta pelo modelo educacional vigente e assegurada pela LDBEN 9394/96, requer profissionais ousados e criativos, que superem as práticas assistencialistas e que favoreçam o desenvolvimento integral da criança, trazendo mudanças para práticas pedagógicas e também para a formação docente.

Segundo Kishimoto (2002), a Pedagogia da infância recomendada pelas políticas públi- 
cas, que ensine conhecimentos específicos às crianças em fase de educação infantil, é contrária às propostas dos cursos oferecidos aos profissionais dessa área, já que são os mesmos profissionais que atuam nas séries iniciais do ensino fundamental. Como não há preparação diferenciada para a educação infantil, esses profissionais acabam utilizando as mesmas práticas de "escolarização" das crianças das séries iniciais.

Leite (2002) sustenta que o desenvolvimento integral da criança é uma realidade muito difícil de ser concretizada nas instituições de educação infantil, em decorrência do perfil profissional dos professores desse nível educativo, pois muitos possuem apenas o normal médio, admitido como formação mínima para a docência. Entretanto, os novos tempos trazem para os profissionais de educação infantil a necessidade de formação em cursos superiores.

A pouca exigência quanto à formação dos professores formadores, segundo Leite (2002), pode ser um obstáculo para a promoção de um trabalho integrado e interdisciplinar, que hoje é essencial para a formação docente. E por enfatizarem a prática, muitas vezes distanciam a teoria, provocando uma profissionalização mais rápida, sem conhecimentos fundamentados.

Além disso, segundo Formosinho (2002), o ensino que divide os conhecimentos por disciplinas nas universidades, desvaloriza ainda mais os componentes profissionais da formação. A cultura acadêmica voltada à especialização por disciplinas coloca à disposição de seus universitários conhecimentos abstratos que não proporcionam o desenvolvimento de competências interpessoais, importantes na formação profissional dos educadores da infância.

Para Kishimoto (2002), a prática pedagógica não é vista como área de conhecimento científico e por isso é utilizada somente no final dos cursos e sua inserção como disciplina científica nas universidades não é fácil de acontecer, já que o seu caráter conservador não permite outras formas de organização, principalmente aquela que leve o aluno a enxergar além do que é permitido. O modelo de organização disciplinar estruturado em conteúdos impediu a versatilidade dos docentes na atuação da educação infantil como também distanciou a teoria da prática.

Formosinho (2002) afirma que a prática docente dos seus formadores no curso de formação inicial e as práticas de organização do ensino são parte integrante e primordial no processo de formação pedagógica dos futuros professores, já que oportunizam o conhecimento de outros métodos e técnicas diferentes daqueles vivenciados no ensino médio, ampliando suas experiências que futu- 
ramente poderão servir para sua atuação docente.

A promoção de uma profissionalidade docente deve capacitá-los para refletir criticamente e motivá-los a buscar soluções para os problemas contidos na prática educativa. Sendo assim, Formosinho (2002) ressalta que esse tipo de formação não é almejado apenas pelas instituições, mas também pela sociedade que ganhará uma educação de melhor qualidade, o que demanda uma preparação sólida e conhecimentos fundamentados. Além disso, esse tipo de formação permite ter mais ênfase na carreira profissional, o que não descarta a necessidade da educação continuada.

É necessário que as universidades construam um espaço para o estudo da criança, fazendo com que os profissionais se voltem e se empenhem nessa área. $\mathrm{Na}$ estrutura específica de educação infantil que deve ser organizada internamente nas instituições, deve-se unir teoria e prática, para que os profissionais possam recorrer aos conhecimentos fundamentais para a solução dos problemas da prática, e é por esse motivo, que há a ênfase das universidades na formação de docentes, na produção do saber a partir da investigação e da reflexão sobre o ensino e a educação.

Formosinho (2002) ressalta que a profissão docente é de natureza complexa e multifacetada e não é uma atividade apenas intelectual, envolvendo além do ensino, o cuidado, e por isso, há a integração das dimensões artesanais e artísticas, de grande importância para o desenvolvimento humano. É necessário criar uma cultura universitária profissional na formação de professores para que se produzam incessantemente conhecimentos importantes para a atuação docente, que estejam de acordo com a construção de uma educação democrática, lugar de várias culturas, comprometida com a comunidade e voltada para a resolução dos problemas sociais.

Silva (2002) afirma que não é de se duvidar que a qualificação dos profissionais de educação infantil seja algo positivo, mas vale ressaltar que o desenvolvimento profissional só acontecerá realmente se as agências que cuidam da formação dos profissionais partirem do pressuposto que a educação é prática que acontece entre os sujeitos e que, nessa relação, ambos se desenvolvem, constroem e reconstroem significados de si, dos outros e do mundo.

Neste sentido, creches e pré-escolas devem nortear o seu trabalho a partir de uma proposta pedagógica que permita a sua interação com outras pessoas, e, em meio ao grupo, nas situações que se estabelecem, possam se reconhecer como pessoas que pensam diferente e que possuem características e necessidades individuais. 
Silva (2002) ressalta que as creches e educadoras que se constituíram às margens do sistema educacional passam a construir sua identidade na dinâmica das novas relações sociais que estabelecem. A nova forma de se definir como educadora e não mais usarem termos como berçaristas, monitoras ou pajem é o resultado vivo do trabalho que as agências formadoras vêm tendo ao longo dos anos com esses sujeitos, suscitando, junto a eles, questionamentos sobre o trabalho assistencial e compensatório que até então era realizado nas creches.

Ainda assim, para Silva (2002), não é difícil perceber que o profissional de educação infantil vive, independentemente de sua qualificação, uma crise de identidade, quando o trabalho é voltado para crianças de 0 a 5 anos de idade, por ainda persistir em nossa cultura a ideia de creche como lugar de cuidado e extensão da família, por causa da sua tenra idade.

Segundo Kramer (2002), atualmente, os efeitos da globalização trazem à tona alguns questionamentos sobre a necessidade de se qualificar, já que os docentes muitas vezes são submetidos a péssimas condições de trabalho e de salário e confinados em ambientes mínimos, limitados ao realizarem propostas de trabalho polivalentes.

Os problemas passados e os recentes devem ser usados nos cursos de formação, como "pontapé" inicial para a promoção de novas mudanças no âmbito educativo e social, e no mais, devem aumentar a luta por uma formação que contribua para "reconhecer a opressão, manter a indignação, a resistência e ter a utopia de uma sociedade justa e sem discriminação de nenhum tipo, sem exclusão e eliminação” (KRAMER, 2002, p. 128).

Diante deste quadro, pode-se compreender que as dificuldades enfrentadas pela Educação Infantil no país remontam à sua gênese, uma vez que o caráter assistencialista predominava nas iniciativas voltadas à criança, em detrimento do aspecto pedagógico. Muitas lutas foram e ainda são travadas para garantir uma proposta de educação para a criança até cinco anos.

Neste sentido, a valorização docente é fator importante de luta, pois, como foi mencionado, o trabalho com as crianças já foi visto como uma extensão do trabalho com os próprios filhos, não necessitando de formação adequada. As condições de trabalho disponíveis aos profissionais da Educação Infantil também ainda são ponto significativo de reivindicação, uma vez que pesquisas evidenciam o caráter de precariedade de muitas creches e pré-escolas na atualidade (VIEIRA; OLIVEIRA, 2013; LEITE et al., 2011). 
Esta conjuntura vivenciada no cotidiano profissional pode trazer consequências ao professor da Educação Infantil, levando-o a lidar constantemente com fatores estressores, que podem levar ao estresse/mal-estar docente ou até mesmo à síndrome de burnout, apresentados anteriormente.

Em levantamento bibliográfico realizado em periódicos da base SCIELO, nos trabalhos das reuniões da Associação Nacional de Pós-Graduação e Pesquisa em Educação (ANPED) e em teses e dissertações disponibilizadas no Banco de Teses da CAPES (Coordenação de Aperfeiçoamento Profissional de Pessoal de Nível Superior), no período de 2002 a 2012, sobre o trabalho docente na Educação Infantil no país, Vieira e Oliveira (2013, p. 131) concluíram que a realidade "é marcada pela atribuição de obrigações que não possuem respaldo nas condições de realização fornecidas pelo poder público. Situações de estresse, mal-estar, adoecimento e insatisfação laboral foram frequentemente relatadas nos estudos".

Nesta pesquisa, evidenciou-se que a desvalorização social do cuidado e da educação das crianças da educação infantil esteve presente em todos os trabalhos.

Dois processos nas condições de trabalho docente estão, em menor ou maior grau, presentes em todos os estudos analisados: a precarização e a intensificação. Em síntese, o primeiro se refere à atribuição de novas funções e tarefas ao mesmo tempo em que não são fornecidas as condições necessárias para o seu cumprimento. (...) Já o segundo trata da imposição de sobrecarga, seja através da necessidade de realização de atividades extras fora da jornada oficial de trabalho ou mesmo através da baixa remuneração, que exige a complementação salarial por meio do compromisso com outros cargos (VIEIRA; OLIVEIRA, 2013, p. 148).

Decorre deste contexto de dificuldades no exercício profissional na educação infantil o mal estar docente, gerando um cenário de estresse diário ao professor, que pode desencadear uma série de reações físicas e mentais, além de levar à insatisfação com o próprio trabalho.

Leite et al. (2011) também realizaram pesquisa sobre as condições de trabalho de 10 professoras de Educação Infantil do Laboratório de Desenvolvimento Infantil (LDI), localizado no campus da Universidade Federal de Viçosa (UFV), no município de Viçosa (MG). Seus resultados indicaram "fatores que contribuíam para o estresse no desenvolvimento do trabalho, considerando o esforço mental e físico que são exigidos em tempo integral". Desta forma, os autores constataram a necessidade de "uma proposta de ação para promover melhores condições da atividade laboral a fim de possibilitar aos professores uma melhor qualidade de vida" (LEITE et al., 2011, p. 1).

Os dois estudos apresentados, Vieira e Oliveira (2013) e Leite et al. (2011), evidenciam a preocupação com a Educação Infantil e suas condições objetivas de existência junto a professores 
e crianças até cinco anos. Os resultados são inquietantes na medida em que lançam luz na presença de fatores estressantes que podem incidir sobre o professor, atingindo por consequência às crianças.

Neste contexto, Wagner (2004) realizou pesquisa em cinco instituições de educação infantil da rede privada e pública da cidade de Porto Alegre (RS), com o objetivo de investigar os níveis de burnout no trabalho de professores e educadores assistentes. Para isto, a pesquisadora utilizou, dentre outros instrumentos, questionários e entrevistas com os educadores e com a direção e coordenação pedagógica das instituições participantes da pesquisa.

Os resultados indicam que os educadores que não destinavam tempo a atividades de lazer estavam mais cansados emocionalmente e que o número de alunos por turma influenciou significativamente os níveis de burnout.

Os participantes da pesquisa consideraram como baixo seu estresse no trabalho, atribuindo ao relacionamento com os familiares das crianças o principal fator estressor. "Constatou-se, portanto, que as características do trabalho e a exigência das relações interpessoais são os possíveis fatores desencadeantes da síndrome no grupo amostrado segundo os participantes da pesquisa” (WAGNER, 2004, p. 5).

Desta forma, este estudo contribui com a temática proposta à medida que problematiza o cotidiano profissional dos professores da Educação Infantil, indicando a presença de fatores estressores e como os profissionais lidam com a situação. Destaca-se a percepção dos próprios professores quanto ao seu ofício, concebendo como baixo o estresse advindo do trabalho e indicando o relacionamento com a família como o fator problemático enfrentado.

Neste contexto, objetivando também contribuir ao debate referente ao estresse docente na Educação Infantil, realizou-se pesquisa com professores de creche de um município do Estado do Rio de Janeiro, o que será apresentado a seguir.

\section{Pesquisando o estresse docente em uma cidade do Estado do Rio de Janeiro}

A fim de verificar a presença de fatores estressores no cotidiano profissional de professores de creches, realizou-se pesquisa de campo, através da técnica de questionário, com professores que atuam com crianças de 0 a 3 anos, em efetivo trabalho nas salas em creches municipais, urbanas, 
de uma cidade do Estado do Rio de Janeiro/Brasil. A amostra foi composta de 100 professores que concordaram em contribuir com esta pesquisa.

Onze creches foram visitadas, mas somente nove aceitaram participar da pesquisa, que durou dois dias e foi realizada no mês de outubro de 2013. As creches que aceitaram fazer parte da pesquisa foram receptivas e quando foi possível ter um contato direto com os professores, o trato foi diferenciado, alguns descartaram o prazo, entregando o questionário respondido na mesma hora. Entretanto, embora cento e trinta questionários tenham sido distribuídos, somente 100 foram preenchidos e devolvidos.

O questionário continha perguntas de múltipla escolha e questões fechadas e abertas. O desenvolvimento das perguntas pretendeu verificar o estresse dos professores na Educação Infantil e, para isto, escolheu-se um número reduzido de perguntas de modo a ajudar o preenchimento/ retorno dos questionários. A tabulação das informações coletadas a partir do questionário permitiu fazer algumas observações, apresentadas abaixo.

A pergunta inicial do questionário referia-se ao tempo de serviço do professor. Certificouse que a amostra era composta por $22 \%$ dos professores com menos de 5 anos de profissão; $49 \%$ possuíam entre 5 e 10 anos, $17 \%$ possuíam entre 10 e 15 anos de tempo de serviço e $12 \%$ dos professores possuíam mais de 15 anos de experiência.

Indagados sobre o prazer de atuar na creche, $88 \%$ dos professores participantes da pesquisa revelaram que sentem prazer, enquanto $12 \%$ afirmaram sentir prazer às vezes. Nenhum deles afirmou não ter prazer em atuar na creche.

Em seguida foi pedido que esclarecessem o porquê de sua resposta. Assim, do total dos que afirmaram sentir prazer ao trabalhar na creche, $29 \%$ relacionaram o seu prazer ao fato de estar ali por vontade própria, como mostra as palavras de um(a) participante da pesquisa:

"Porquê escolhi essa profissão, então apesar dos desafios estou pronta para enfrentá-los com muito amor (amo o que faço)".

Isto parece indicar que a escolha pessoal é relevante para enfrentar os desafios, já que quando se exerce a profissão escolhida, provavelmente há maior motivação para enfrentar as dificuldades profissionais cotidianas.

O próximo fator relacionado à promoção de prazer ao atuarem na creche, está relacionado 
Estresse docente na Educação Infantil: um estudo sobre professores de creches públicas de uma cidade do Estado do Rio de Janeiro

\section{Zero-a-seis}

ao progresso diário das crianças, com 16\% das menções, por acharem que a creche permite ver de perto o desenvolvimento das crianças, supostamente devido ao fato de permanecerem integralmente na instituição.

Outro fator também indicado como promotor de prazer ao atuar na creche foi o ambiente de trabalho, com 16\% das menções. Nas palavras dos(as) professores(as):

"Temos uma boa equipe de trabalho."

"Aqui os professores são legais, apesar de cada um ficar envolvido na sua função e não ter muita oportunidade de diálogos, os diretores são excelentes e conquistar essa vaga nesse concurso atualmente para mim foi uma vitória."

Neste contexto, Esteve (1999) ressalta que o isolamento dos professores só os leva à inibição e à rotina e não colabora com as tentativas de solucionar os problemas. A comunicação dentro da instituição é muito importante para que esse profissional consiga realizar uma nova prática educativa.

Para Esteve (1999):

A inovação educativa ocorre sempre com a presença de equipes de trabalho; há professores que, embora trabalhem individualmente, compartilham com outros colegas seus êxitos e suas dificuldades, adaptando e melhorando continuamente, nessa comunicação, os métodos, objetivos e conteúdos (ESTEVE, 1999, p. 143).

Nesse sentido, o diálogo com professores que já atuam é relevante para o entendimento de que a mudança é possível. Para Lantheaume (2012), o trabalho em equipe, além de desenvolver a confiança no outro, permite vivenciar o gosto da solidariedade.

Outro fator relacionado ao prazer em atuar na creche é o contato com as crianças, com 7\% das menções. Nas palavras do(a) professor(a):

"Ao ensinar você aprende e ao aprender você ensina."

Sobre esse fato, pode-se refletir sobre a importância da relação interpessoal entre o professor e a criança, uma vez que a educação só acontece a partir das interações sociais. Uma boa relação pode trazer tanto para a criança quanto para o professor o prazer de conviver e aprender juntos.

Ainda quanto a esta mesma pergunta, foi citado menos chance de agressões com apenas $1 \%$. Os outros $19 \%$ assinalaram a opção indicativa de sentirem prazer ao atuar na creche, mas não responderam por que. Ou seja, esta questão apresentava as opções sim, não e às vezes, mas havia um complemento solicitando que o professor explicasse o porquê de sua resposta, o que não foi feito por 
$19 \%$ dos professores que responderam que sentem prazer ao atuar na creche.

Entre os professores que disseram às vezes sentir prazer em atuar na creche, $6 \%$ deles questionaram a falta de condição de trabalho, principalmente quanto ao número de crianças nas salas. Segundo um(a) professor(a) participante da pesquisa:

"Quando as salas estão super lotadas não da para fazer um bom trabalho".

Esta fala expressa bem a influência dos fatores contextuais na promoção de uma nova prática e como incidem diretamente no bem-estar dos profissionais, já que a dificuldade de realizar o trabalho lhe tira o prazer de atuar. O próximo fator aliado a este é falta de apoio dos pais (1\%), dificuldade de unir teoria e prática (1\%) e 4\% não responderam.

Perguntados se consideram sua profissão estressante, $72 \%$ dos professores responderam que sim, enquanto apenas $28 \%$ dos participantes não classificaram a profissão como estressante.

Quanto à relação entre o prazer e o estresse, observa-se que apesar de 88\% dos professores participantes da pesquisa sentirem prazer ao atuar na creche, $72 \%$ consideram a profissão estressante. Aguiar e Almeida (2008) declaram que o prazer e o sofrimento se revezam constantemente no ambiente profissional, já que na função de ensinar muitos sentimentos estão envolvidos.

A próxima questão investigava se os docentes tiveram preparação no curso de formação inicial para lidar com o estresse presente na docência. Dos participantes, 58\% afirmaram que não, $32 \%$ disseram que estavam preparados em parte, $9 \%$ disseram que sim e $1 \%$ não respondeu.

No que diz respeito aos cursos de formação inicial, Esteve (1999) sustenta que vêm se fundamentando em normas e traçam um tipo de profissional dissociado das contradições da prática. Por isso, ao se depararem com uma realidade totalmente diferente, os professores acabam ansiosos por não conseguirem atuar conforme os ideais transmitidos em sua formação.

De acordo com Kishimoto (2002), não é de se negar que os cursos de Pedagogia atualmente velem por profissionais pesquisadores que sejam capazes de investigar a prática pedagógica a partir da análise da educação como um todo, desde os aspectos do cotidiano à interação professor/aluno. O que vale ressaltar é que a estrutura curricular dos cursos não está de acordo com esse tipo de profissional que se quer formar.

Perguntados se levam os problemas do trabalho para a vida pessoal, $78 \%$ responderam que não, 20\% responderam que sim e 2\% não responderam. Sobre este fato, Malagris (2002) ressalta que 
não levar os conflitos diários do trabalho para sua vida particular seria um meio de conviver com eles e não deixar que atinjam seu bem estar.

Em seguida, foi perguntado se o(a) professor(a) já precisou se afastar por atestados e licenças médicas devido ao estresse provocado pela sala de aula. Dos participantes da pesquisa, $81 \%$ disseram que não e 19\% disseram que sim. Isto pode indicar que os professores talvez não estejam precisando se afastar ou que estejam procurando outras formas de aliviar a tensão do trabalho, como por exemplo, uma folga por mês, prática informal muito comum nas creches do município.

Ao interrogar se a creche reserva algum tempo para o trabalho coletivo e reuniões em equipes, houve um empate entre os professores que afirmaram que $\operatorname{sim}, 35 \%$, e os que disseram às vezes, $35 \%$, contra 29\% que disseram não. Apenas 1\% não respondeu.

Segundo Lantheaume (2012), a prática do trabalho coletivo é uma necessidade atual para lutar por melhores condições de trabalho e outros. Por isso tem aumentado dentro das instituições, pois pode trazer de volta uma identidade profissional, que a tempo se perdeu devido ao discurso individualista na docência. Quando as normas são direcionadas a alguns profissionais, e não a todos, cria-se certa exaustão. O discurso coletivo, ao mesmo tempo em que contribui para delimitar regras, protege os professores, já que ao compartilhar as dificuldades, o problema deixa de ser pessoal para se tornar público.

$\mathrm{Na}$ sondagem feita para saber se o estresse do professor de educação infantil é tema abordado nos cursos de formação continuada, $65 \%$ afirmaram que não, $22 \%$ disseram às vezes, $11 \%$ disseram que sim e $2 \%$ não responderam.

Segundo Malagris (2002), é necessário que o estresse seja tema de estudos para que se possa explicá-lo melhor, e, por conseguinte, criar melhores maneiras de lidar com ele no trabalho e na vida.

Neste contexto, torna-se necessário ofertar aos professores de Educação Infantil uma formação em serviço "como prática social de reflexão contínua e coerente com a prática que se pretende implementar" (KRAMER, 2002, p. 121).

Antes de qualquer processo de formação, seja inicial ou continuada, é necessário conhecer quais são as concepções prévias em relação ao trabalho nas creches e conhecer as experiências de formação que esse profissional obteve ao longo do tempo. Segundo Silva (2002), para que haja a 
delimitação de uma identidade profissional, os formadores devem:

[...] compreender a maneira como se estrutura o trabalho hoje desenvolvido por essas profissionais nas creches. Conhecê-lo junto como quem o desempenha, no sentido de explicitar os fundamentos que embasam essas práticas, contribuindo para torná-las mais conhecidas para as próprias educadoras que as exercem (SILVA, 2002, p. 207).

Portanto, os formadores devem conhecer a natureza do trabalho feito nas instituições para organizar processos de formação e levar os licenciandos a problematizar suas próprias práticas, pois muitas vezes a forma como o professor de Educação Infantil conduz seu trabalho é resultado não de uma formação específica, mas de concepções pré-estabelecidas de sua cultura.

Por fim, os professores foram convidados a indicar o que poderia ser feito para diminuir o estresse na creche. Dos participantes, 35\% responderam que reduzir o número de crianças por sala seria uma das maneiras de diminuição do estresse, e, aliado a este, $28 \%$ indicaram a necessidade de ter auxiliares de turma, pois de acordo com um(a) professor(a):

“O número de alunos por salas não é compatível com o número de funcionários. Tendo o professor que varrer, forrar cama, além de seu serviço que é o Pedagógico”.

No desabafo de um(a) professor(a):

"Se tivermos auxiliares de turma todos os dias e turmas menos lotadas, e com prazo de matrículas ajudaria bastante. (...) Levamos um tempo para colocarmos as crianças em ordem para se adaptarem (...) e quando estamos entrando no ritmo matriculam-se mais alunos que geralmente chega chorando e desestrutura o resto da turma e isso é o ano inteiro (...). A visão da creche ainda é a de depósito, somos consideradas babás (...)”.

A estrutura física e pedagógica também foi indicada como fator que poderia diminuir o estresse do professor na creche com $11 \%$ das menções, $7 \%$ cursos, $6 \%$ participação da família, 4\% tempo para planejamento, 3\% atividades em equipe e outros. Os 6\% restantes não apontaram o que poderia ser feito para diminuir o estresse na creche.

Sendo assim, os resultados da pesquisa indicam a presença de fatores estressores no cotidiano dos professores de creches municipais de uma cidade do Estado do Rio de Janeiro que participaram desta pesquisa. Tais fatores parecem estar ligados, dentre outros, ao excesso de crianças nas salas associado à falta de funcionários, falta de estrutura física e pedagógica, assim como à preparação deficiente dos cursos de formação inicial e à ausência de discussão do tema nos cursos de formação continuada. 
No entanto, não bastará abordar o estresse docente nos cursos de formação, seja inicial ou continuada, se o poder público não participar das discussões sobre o tema e intervir, sobretudo, na questão de maior investimento na Educação Infantil.

\section{Considerações Finais}

Neste trabalho, buscou-se apresentar os resultados de pesquisa realizada para verificar a presença de fatores estressores no cotidiano profissional de professores de creches, o que além de estar relacionado à saúde dos profissionais, pode ainda afetar diretamente a educação das crianças nas instituições de Educação Infantil.

Diante da pesquisa realizada em uma cidade do Estado do Rio de Janeiro com 100 professores de creches municipais, pode-se indicar a presença de fatores estressores no contexto destes profissionais, tais como o excesso de crianças por professor, falta de estrutura física e pedagógica, preparação insuficiente nos cursos de formação inicial e continuada, dentre outros.

Quando os professores participantes da pesquisa respondem que não estão preparados para lidar com o estresse da Educação Infantil, parecem apontar uma possível deficiência na sua formação a respeito do tema, pois podem ter sido vítimas de uma formação que não esteve voltada à realidade do cotidiano das creches e pré-escolas do país, sinalizando ainda uma possível desarticulação da formação continuada com o cotidiano da Educação Infantil.

A profissão docente apresenta sua complexidade: atuar com o mínimo de recursos, ensinar a uma variedade de indivíduos, não desvalorizando a cultura de nenhum deles, ser responsabilizado por transmitir valores etc. Neste contexto, os dados obtidos na pesquisa são relevantes. Dizer que é necessário ter menos crianças nas salas, mais funcionários, melhores condições físicas e pedagógicas para diminuir o estresse da creche revela a causa do desconforto.

Uma renovação pedagógica na creche não se faz em uma sala com trinta crianças, quando foi construída para comportar quinze. O poder público tem garantido a inserção da criança na creche, mas parece não ter se adequado à educação da massa que passou a atender.

A pesquisa demonstra a urgência em investimentos para a educação, não só para benefício das crianças, mas também para assegurar a saúde dos profissionais, até porque ninguém consegue trabalhar dinamicamente se não estiver saudável física e mentalmente. 
Entretanto, o êxito em seu exercício profissional e a oportunidade de ter de volta o bem estar que o contexto conflituoso lhe tirou não é possível acontecer se o professor permanecer sozinho. Faz-se necessário o acolhimento do outro, pois juízos de valor só pioram seu sofrimento. A união dos colegas de trabalho torna-se aspecto relevante para os educadores, principalmente para aqueles que estão chegando pela primeira vez à docência.

Neste cenário atual, o alívio para o estresse docente talvez venha por medicamentos em casos mais graves, mas vale ressaltar que enquanto não houver valorização, sobretudo por melhores salários, recursos, condições de trabalho e melhor formação, a solução para o quadro de estresse docente parece distante.

\section{Referências}

AGUIAR, Rosana Márcia Rolando; ALMEIDA, Sandra Francesca Conte de. Mal-estar na educação: o sofrimento psíquico de professores. Curitiba: Juruá, 2008.

ARCHANGELO, Ana. O amor e o ódio na vida do professor: passado e presente na busca de elos perdidos. - 2. ed. - São Paulo : Cortez, 2011.

BRASIL. Lei de Diretrizes e Bases da Educação Nacional, no . 9.394, de 20 de dezembro de 1996. Disponível em: http://www.planalto.gov.br.ccivil_03/leis/9394.htm Último acesso em: 21/09/2015.

ESTEVE, José Manuel. O mal-estar docente: a sala de aula e a saúde dos professores. Bauru, SP: EDUSC, 1999.

FORMOSINHO, João. A universidade e a formação de educadores de infância: potencialidades e dilemas. IN: MACHADO, Maria Lúcia de A. (Org.). Encontros e desencontros em educação infantil. São Paulo: Cortez, 2002.

KISHIMOTO, Tizuko Morchila. Encontros e desencontros na formação dos profissionais de educação infantil. IN: Machado, Maria Lúcia de A (Org.). Encontros e desencontros em educação infantil, São Paulo: Cortez, 2002.

KRAMER, Sônia. Formação de profissionais de educação infantil: questôes e tensóes. IN: Machado, Maria Lúcia de A (Org). Encontros e desencontros em educação infantil. São Paulo: Cortez, 2002.

LANTHEAUME, Françoise. Professores e dificuldades do ofício: preservação e reconstrução da dignidade profissional. Cadernos de Pesquisa, v. 42, no 146, p.368-387, maio/ago. 2012.

LEITE, Maria Aparecida; SALGADO, Sara Maria Lopes; MAFRA, Simone Caldas Tavares; SILVA, Vânia Eugênia da. Professores em educação infantil: uma análise ergonômica a partir das condiçóes de trabalho do Laboratório de Desenvolvimento Infantil (LDI) da Universidade Federal de Viçosa-MG. V Workshop de Análise Ergonômica do Trabalho - UFV/ II Encontro Mineiro de Estudos em Ergonomia, Universidade Federal de Viçosa (UFV), 2011. 
LEITE, Yoshie Ussami Ferrari. Formação dos profissionais em educação infantil: Pedagogia x Normal Superior. IN: MACHADO, Maria Lúcia de A. (Org.). Encontros e desencontros em educação infantil. São Paulo: Cortez, 2002.

LIPP, Marilda. Soluçóes criativas para o stress. IN: LIPP, Marilda (Org.). O Stress do Professor. Campinas, SP: Papirus, 2002.

MALAGRIS, Lucia Novaes. O professor, o aluno com distúrbios de conduta e o stress. IN: LIPP, Marilda (Org.). O Stress do Professor. Campinas, SP: Papirus, 2002.

MELEIRO, Alexandrina da Silva. O stress do professor. IN: LIPP, Marilda (Org.). O Stress do Professor. Campinas, SP: Papirus, 2002.

OLIVEIRA, Zilma de Moraes Ramos de. Educação infantil: fundamentos e métodos.- 5.ed.- São Paulo: Cortez, 201.

REINHOLD, Helga. O burnout. IN: LIPP, Marilda (Org.). O Stress do Professor. Campinas, SP: Papirus, 2002.

SILVA, Isabel de Oliveira. A profissionalização do professor da educação infantil: questôes sobre a formação dos profissionais que estão em serviço. IN: MACHADO, Maria Lúcia de A. (Org.). Encontros e desencontros em educação infantil. Sáo Paulo: Cortez, 2002.

VIEIRA, Lívia Fraga; OLIVEIRA, Tiago Grama. As condiçôes do trabalho docente na educação infantil no Brasil: alguns resultados de pesquisa (2002-2012). Revista Educação em Questão, Natal, v. 46, n. 32, p. 131-154, maio/ago. 2013.

WAGNER, Dione Pereira. Síndrome de Burnout: um estudo junto aos educadores (professores e educadores assistentes) em escolas de Educaçáo Infantil. Mestrado Profissional em Engenharia de Produção- Ênfase em Ergonomia. Universidade Federal do Rio Grande do Sul. Porto Alegre, 2004. 